\title{
Factors Influencing Hyponatremia in Hospitalized Diabetic Patients- A Cross Sectional Study
}

\author{
Ahmed SS ${ }^{1}$, Nur F ${ }^{2}$, Ullah MR ${ }^{3}$, Mamun AA ${ }^{4}$, Chowdhury $\mathrm{MTI}^{5}$, Laila $\mathrm{TR}^{6}$, Khan MAM${ }^{7}$
}

\begin{abstract}
Hyponatremia is a very common electrolyte imbalance in admitted diabetic patients which leads to substantial morbidity and mortality. There is no existing record for profiling of hyponatremia in Bangladeshi diabetic subjects. The objective of this study was to find out the factors influencing hyponatremia and associated co-morbidities in admitted diabetic patients of a tertiary care hospital. Samples were selected from all adult nonpregnant diabetic patients with serum sodium level $<135 \mathrm{mmol} / \mathrm{L}$ irrespective of their cause of admission. A total number of 115 admitted diabetic patients with hyponatremia were studied. Informations were collected in a semi structured data collection form for analysis. Hyponatremia was found to be more common in the aged (47\%) and female populations (63.5\%). Vomiting was found to be the most common factor (51.3\%) causing hyponatremia in the admitted diabetic patients. Other common factors influencing hyponatremia were diarrhea, sweating, severe hyperglycemia, diabetic ketoacidosis and drugs especially diuretics. The commonest co-morbid condition associated with diabetes was hypertension. Thiazide diuretics should be used with caution in the elderly who are prone to develop hyponatremia.
\end{abstract}

Keywords: Hyponatremia, Electrolyte Imbalance, Diabetes Mellitus

\section{Introduction}

Hyponatremia is defined as a serum sodium $\left(\mathrm{Na}^{+}\right)$ concentration less than $135 \mathrm{mmol} / \mathrm{L}^{1-4}$ and is a common electrolyte abnormality in diabetes mellitus (DM). It is often

1. Corresponding Author:

Prof. Dr. Sheikh Salahuddin Ahmed, MBBS, FCPS

Head of the Department of Medicine

Bangladesh Institute of Health Sciences \& Hospital, Dhaka

E mail: drsksalahahmed@yahoo.com

2. Dr. Fazle Nur, MBBS, DEM, MPH

Consultant, Department of Endocrinology

Bangladesh Institute of Health Sciences \& Hospital, Dhaka

3. Dr. Md Rahamat Ullah, MBBS, CCD

Registrar, Department of Medicine

Bangladesh Institute of Health Sciences \& Hospital, Dhaka

4. Dr. Abdullah Al Mamun, MBBS, CCD

Medical Officer, Department of Medicine

Bangladesh Institute of Health Sciences \& Hospital, Dhaka

5. Dr. Md. Tauhidul Islam Chowdhury, MBBS, MD

Assistant Professor of Neurology

National Institute of Neuroscience \& Hospital, Dhaka

6. Dr. Tarafdar Runa Laila, MBBS, FCPS, MS Assistant Professor, Department of Obstetrics \& Gynecology Bangabandhu Sheikh Mujib Medical University, Dhaka

7. Dr. Md. Abdul Mahid Khan, MBBS, D Card, MRCP Assistant Professor, Department of Cardiology Bangladesh Institute of Health Sciences (BIHS) 125/1, Darus Salam, Mirpur-1, Dhaka 1216, Bangladesh detected asymptomatically, or in a patient with non specific symptoms (like anorexia, nausea, lethargy, headache, malaise, muscle cramps) or may also be associated with profound disturbances of cerebral function attributable to cerebral edema ${ }^{1}$. Symptoms often do not occur until the serum $\mathrm{Na}^{+}$ concentration drops below $125 \mathrm{mmol} / \mathrm{L}^{5}$. Hyponatremia can cause substantial morbidity and mortality, and ironically, incorrect treatment can add to the problem. Treatment of hyponatremia involves first determining the cause and then correcting this when possible.

Hyponatremia is classified into 3 groups according to clinical history and volume status ${ }^{1,5}$ : (i) Hypovolemic hyponatremia $\left(\mathrm{Na}^{+}\right.$deficit with a relatively smaller water deficit)- like gastrointestinal loss (vomiting, diarrhea); insensible loss (sweating, fever); renal loss: diuretics, salt wasting nephropathy, mineralocorticoid deficiency and cerebral salt wasting (ii) Euvolemic hyponatremia (water retention alone)- like Syndrome of Inappropriate Anti Diuretic Hormone (SIADH), hypothyroidism, primary polydipsia, glucocorticoid deficiency and (iii) hypervolemic hyponatremia $\left(\mathrm{Na}^{+}\right.$retention with relatively greater water retention)- like heart failure, hepatic cirrhosis, nephrotic syndrome \& chronic renal failure.

Hypertonic hyponatremia is usually due to hyperglycemia. Transient hypertonic hyponatremia may also occur due to osmotic shifts of water out of cells caused by mannitol infusion and use of radiocontrast agents ${ }^{1,2}$. Artefactual causes of isotonic hyponatremia (pseudohyponatremia) can occur in the presence of severe hyperlipidemia or hyperproteinemia ${ }^{1,2}$, and now rarely occurs as a result of improved laboratory techniques for measuring serum $\mathrm{Na}^{+}$. Severe hyponatremia can develop after elective surgery in healthy patients ${ }^{2}$. Medical procedures such as colonoscopy have also been associated with hyponatremia ${ }^{2}$. Massive absorption of irrigant solutions that do not contain sodium (e.g., those used during transurethral prostatectomy) can cause severe and symptomatic hyponatremia ${ }^{6}$. The hyponatremia of beer potomania occurs in patients who consume large amounts of beer $^{3}$. Beer is very low in protein and salt content.

It is well known that hyperglycemia is associated with a decrease in serum $\mathrm{Na}^{+}$concentration ${ }^{7}$. Glucose being an osmotically active molecule, hyperglycemia can induce a fall in serum $\mathrm{Na}^{+}$levels by shifting water from intra-cellular to extra-cellular compartments. It has been calculated that serum $\mathrm{Na}^{+}$falls by 1.6 to $2.4 \mathrm{mmol} / \mathrm{L}$ for every $5 \mathrm{mmol} / \mathrm{L}$ rise in serum glucose levels ${ }^{8}$. It is also well known that the hyperglycemia in diabetic ketoacidosis can cause osmotic diuresis leading to dehydration and electrolyte loss, particularly of $\mathrm{Na}^{+}$and potassium ${ }^{8}$. Example of drugs used for treating comorbid conditions like hypertension in diabetes are thiazide or loop diuretics, may also result in hyponatremia.

Data regarding the incidence and influencing factors of hyponatremia in DM in our country is limited. The objectives 
of this study were (i) to identify the factors responsible for hyponatremia in admitted diabetic patients (ii) to find out the comorbidities associated with DM and (iii) to assess the demographic status of the admitted diabetic patients and evaluate their effect on hyponatremia.

\section{Materials and Methods}

Study Design: It was a cross sectional study. Study Subjects: The target population of this study was adult diabetic patients. Place of the study: The study was conducted in the in-patients department of Medicine at Bangladesh Institute of Health Sciences (BIHS) and Hospital, Dhaka. Study Period: This study was carried out for 9 month from January 2013 to September 2013.

\section{Inclusion criteria:}

*Adult (> 18 years) male and female patients

*Suffering from DM

*Admitted in the department of Medicine in BIHS and Hospital

*Identified to have hyponatremia on admission (admission serum $\mathrm{Na}^{+}$being $<135 \mathrm{mmol} / \mathrm{L}$ )

\section{Exclusion Criteria:}

*Unwilling to be included in the study

*Persons with mental illness

*Pregnant diabetic patient

Sample size: This sample size was a total 115. Sampling method: Sampling was made from all the admitted diabetic patients found to have hyponatremia (community acquired hyponatremia) irrespective of their cause of admission and fulfilling the inclusion \& exclusion criteria as mentioned. Data collection instrument: Semi-structured questionnaire and checklist. Data collection technique: All participants were face to face interviewed followed by physical examination. Subjects were advised to give blood samples from the antecubital vein using disposable plastic syringe. Random blood glucose (RBG) on admission was done by bedside standardized glucometer from finger prick. Bedside readings by glucometer indicated "high" when RBG was $\geq 30$ $\mathrm{mmol} / \mathrm{L}$; which we have considered as severe hyperglycemia in this study. Urine for routine examination was collected in a test tube. Urine ketone bodies were estimated bedside by reagent strip method. All the necessary informations were endorsed in the data collection sheet. Data editing, coding, cleaning, and analysis: All the responses obtained from the patients were coded numerically and entered into the Statistical Package in Social Sciences (SPSS) windows version 16.0 software program for analysis.

\section{Results}

The study was carried out among 115 diabetic patients having hyponatremia on admission. Table 1 shows distribution of patients according to age, sex, residence, education, occupation and economic status of the total study sample of 115 . Of the 115 subjects $9.5 \%$ belonged to the age group of 20 to 39 years, $43.5 \%$ to the age group 40 to 59 years, and most $(47.0 \%)$ belonged to the age group of 60 years and above. The lowest age was 20 years and the highest was 80 years. Their mean age was 56.1 years and SD was \pm 13.5 years. Total number of male respondents was $42(36.5 \%)$ and female, $73(63.5 \%)$. Majority of the patients $(76.5 \%)$ belonged to urban population. The rest belonged to semiurban $(13.0 \%)$ or rural area $(12.2 \%)$. Most of the respondents (41.7\%) had junior school certificate (JSC) level of education or less, followed by $(26.0 \%)$ higher secondary school certificate (HSC), graduation and above level (15.7\%) and no education at all (16.4\%). Most were involved in household work $(54.8 \%)$ followed by self employed $(23.5 \%)$, doing government or private service $(09.5 \%)$ and unemployed/ dependant $(12.2 \%)$. Financial condition was found to be of average in $46.1 \%$, good in $32.2 \%$ and below average in 21.7 $\%$ of the study subjects.

Table 1: Socio-demographic Profile of the study samples $(n=115)$

\begin{tabular}{lcc}
\hline \multicolumn{1}{c}{ Variables } & Number & Percentage \\
\hline Age(yrs) & 11 & 09.5 \\
$20-39$ & 50 & 43.5 \\
$40-59$ & 54 & 47.0 \\
$60+$ & & \\
Sex & 42 & 36.5 \\
Male & 73 & 63.5 \\
Female & & \\
Residential Area & 88 & 76.5 \\
Urban & 13 & 11.3 \\
Semi-urban & 14 & 12.2 \\
Rural & & \\
Education & 19 & 16.4 \\
No formal schooling & 48 & 41.7 \\
Up to JSC (up to class VIII) & 37 & 26.0 \\
Up to HSC (up to class XII) & 30 & 15.7 \\
Graduation and above & 18 & 23.5 \\
Occupation & & \\
Service (government/private) & 11 & \\
Self-employed/business & & \\
Household work & & \\
Unemployed/dependant & & \\
Financial Condition & & \\
Average (13000-30000 taka/ & & \\
month) & & \\
Beod (>30000 taka/month) & & \\
month) & & \\
\hline
\end{tabular}

In our study we have considered hyponatremia when serum sodium level was found $<135 \mathrm{mmol} / \mathrm{L}$. The lowest value of serum $\mathrm{Na}^{+}$in this study was $107 \mathrm{mmol} / \mathrm{L}$. The mean value 
of serum $\mathrm{Na}^{+}$level was $127 \mathrm{mmol} / \mathrm{L}$ with standard deviation (SD) of $5.4 \mathrm{mmol} / \mathrm{L}$. Table 2 shows distribution of the patients having different ranges of serum $\mathrm{Na}^{+}$level. It shows that the majority of patients with hyponatremia had serum $\mathrm{Na}^{+}$level ranging from $130-134 \mathrm{mmol} / \mathrm{L}(46.1 \%)$ followed by $28.7 \%$ with serum sodium level of $125-129 \mathrm{mmol} / \mathrm{L}$.

Table 2: Serum sodium concentration of the study subjects $(n=115)$

\begin{tabular}{lll}
\hline \multicolumn{1}{c}{ Serum Sodium in mmol/L } & Number & Percentage \\
\hline $130-134$ & 53 & 46.1 \\
$125-129$ & 33 & 28.7 \\
$120-124$ & 21 & 18.3 \\
$114-119$ & 05 & 04.3 \\
$<115$ & 03 & 02.6 \\
\hline
\end{tabular}

Figure 1 shows the distribution of type of diabetes. Type 2 diabetes (T2DM) was $92.2 \%$ and type 1, 7.8\%. Figure 2 shows the co-morbidities in the diabetic samples at the time of hospital admission. About $66.1 \%$ subjects had Hypertension, 32.2\% had Chronic Kidney Disease (CKD), 18.3\% had Dyslipidemia, 13.0\% had Ischemic Heart Disease (IHD), 5.2\% had Fatty Liver, 4.3\% had Cerebrovascular Disease, and 2.6\% had Congestive Cardiac Failure (CCF).

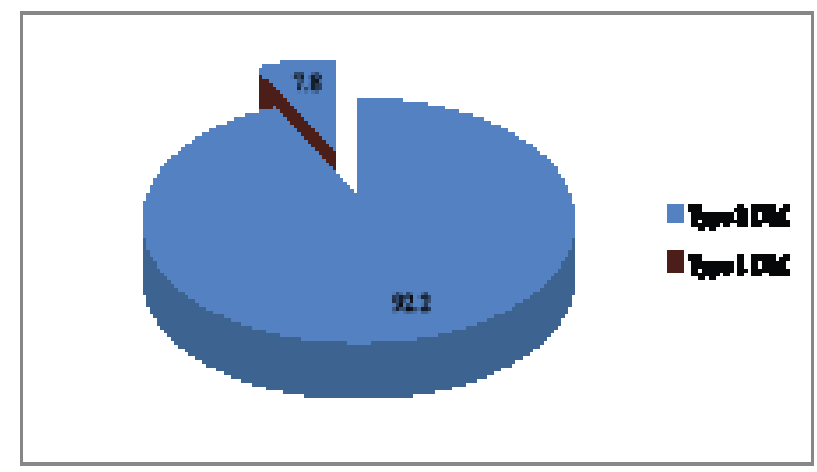

Figure 1: Type of diabetes $(n=115)$

Abbreviation: T1DM, type 1 diabetes; T2DM, type 2 diabetes

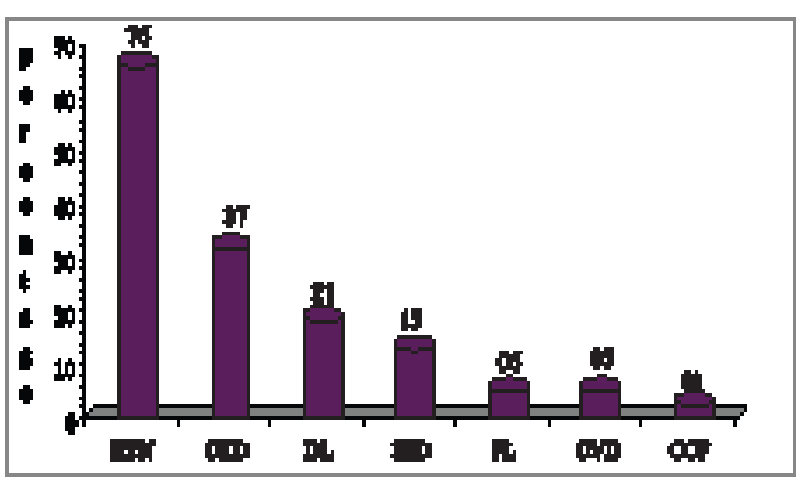

Figure 2: Co-morbidities associated with diabetes $(\mathbf{n}=115)$ : Multiple responses

Abbreviation: HTN, Hypertension; CKD, Chronic Kidney Disease; DL, Dyslipidemia; IHD, Ischemic Heart Disease; FL, Fatty Liver; CVD, Cerebro Vascular Disease; CCF, Congestive Cardiac Failure.
Figure 3 shows diabetic status of the study subjects at the time of hospital admission. Diabetes was found not to be controlled strictly in most of the study patients $(77.4 \%)$. Severe hyperglycemia $(\mathrm{RBG} \geq 30 \mathrm{mmol} / \mathrm{L})$ was present in $15.7 \%$ of the subjects on hospital admission.

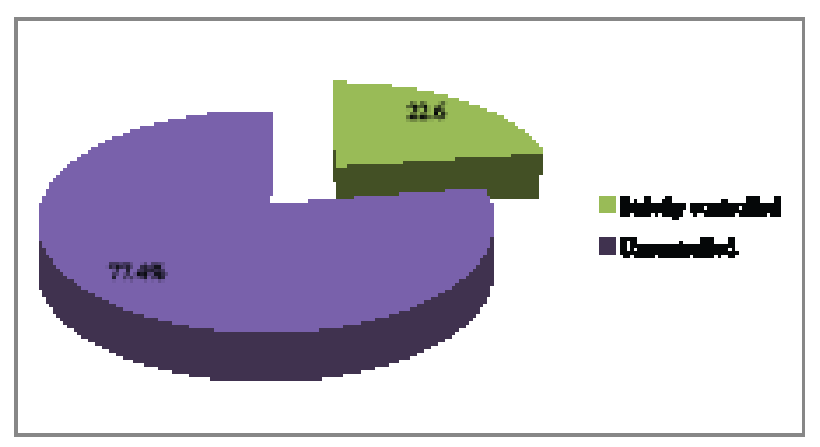

Figure 3: Status of diabetic control on admission $(n=115)$

The factors precipitating hyponatremia revealed on hospital admission is shown in table-3. Vomiting was found the most common cause of hyponatremia $(51.3 \%)$ followed by diarrhea $(26.1 \%)$, severe hyperglycemia $(15.7 \%)$, diabetic ketoacidosis $(12.2 \%)$, pyrexia due to known or unknown cause $(18.3 \%)$, excessive sweating due to pyrexia or other cause $(14.8 \%)$, inadequate salt intake due to severe anorexia or voluntary restriction $(12.2 \%)$, and thiazide induced hyponatremia used for treatment of hypertension $(7.0 \%)$. Hyponatremia in edematous condition due to CCF was $03.5 \%$, CKD was $02.6 \%$ and other cause (like hypothyroidism) was $01.7 \%$. No apparent cause of hyponatremia was found in $04.3 \%$ of case.

Table 3: Factors precipitating hyponatremia $(n=115)$

\begin{tabular}{lcc}
\hline Variables & Number* & Percentage* \\
\hline Vomiting & 59 & 51.3 \\
Diarrhea & 30 & 26.1 \\
Severe hyperglycemia & 18 & 15.7 \\
Diabetic ketoacidosis & 14 & 12.2 \\
Pyrexia & 21 & 18.3 \\
Excessive sweating & 17 & 14.8 \\
Inadequate salt intake & 14 & 12.2 \\
Drug (thiazide) induced & 08 & 07.0 \\
Excessive plain water & 05 & 04.3 \\
intake & & \\
CCF with edema & 04 & 03.5 \\
CKD with edema & 03 & 02.6 \\
Other causes & 02 & 01.7 \\
No apparent cause & 05 & 04.3 \\
\hline
\end{tabular}

*Multiple responses

\section{Discussion}

The main purpose of this study was to find out the precipitating factors responsible for hyponatremia in admitted diabetic patients. It is essential to find out the cause of hyponatremia for a rational management. Studies 
have shown that hyponatremia is common in hospitalized patients and is responsible for significant morbidity and mortality $^{9-12}$. In one study the mortality rate was $20 \%{ }^{13}$. Hyponatremia is a common electrolyte disturbance in the elderly admitted sick patients ${ }^{13}$. Most of the diabetic patients in our study were elderly having age of 60 years and above $(47.0 \%)$. The incidence is much more in the elderly mainly owing to impaired ability to maintain water and electrolyte homeostasis in response to dietary and environmental changes ${ }^{14}$. The sensation of thirst, renal function and tubular concentrating abilities are often impaired in the elderly. In this study $63.5 \%$ of diabetic subjects having hyponatremia were female. In one prospective study on hyponatremia, $60 \%$ of the cases were female ${ }^{14}$. A female preponderance $(55 \%)$ was also seen in another study ${ }^{13}$. Studies have shown that female gender is an important risk factor for the development of severe complications ${ }^{15}$. Chronic hyponatremia in postmenopausal women is common ${ }^{16}$. Most of the patients in our study had multiple co-morbid conditions of which hypertension was the most common $(66.1 \%)$. It was found to be $61 \%$ by a study conducted in Bangladesh Institute of Research and Rehabilitation in Diabetes, Endocrine and Metabolic Disorders (BIRDEM) ${ }^{17}$. Another study also revealed hypertension to be the most common $(69 \%)$ comorbid condition in patients with hyponatremia ${ }^{13}$.

The most common precipitating factor for hyponatremia found in this study was vomiting $(51.3 \%)$ followed by diarrhea $(26.1 \%)$. Severe hyperglycemia associated with hyponatremia was found in $15.7 \%$ of study subjects. Thiazide diuretics used for the treatment of hypertension in the elderly can result in hyponatremia. In this study 7.0 $\%$ of patients receiving thiazides developed hyponatremia. Hyponatremic hypertensive syndrome is a well known entity, the most common association being in patients with essential hypertension receiving thiazide diuretics ${ }^{18}$. Many studies have reported that drugs especially thiazide diuretics are a major cause of hyponatremia in elderly ${ }^{6,14,19}$.

This study shows that most of the patients (46.1\%) with hyponatremia had serum $\mathrm{Na}^{+}$level ranging from 130 $134 \mathrm{mmol} / \mathrm{L}$. Mild hyponatremia, which is common in asymptomatic ambulatory individuals, is considered by many clinicians to be a generally benign finding. However, during the past decade, several community-based studies have shown that mild hyponatremia carries specific morbidity as it has been independently associated with gait and attention deficit, and with an increased risk of falls ${ }^{20}$, bone fractures ${ }^{21}$, and possibly osteoporosis ${ }^{22,23}$. A recent prospective cohort study found that the risk of mortality in individuals with hyponatremia is evident even in mild cases (serum $\mathrm{Na}^{+}$concentration 130-134 mmol/L), which constituted the majority of cases in their study ${ }^{24}$. Importantly, they found only a small difference in the absolute prevalence of hyponatremia when corrected for hyperglycemia, and no effect on the association between hyponatremia and mortality. Studies reveal that outlook of a patient with hyponatremia is governed principally by etiology, and not by serum $\mathrm{Na}^{+}$ level ${ }^{14}$.

Hyponatremia is the most common and important electrolyte abnormality encountered in hospitalized elderly diabetic patients with the potential for significant morbidity and mortality. Women are seen to develop hyponatremia more than men. Hypertension is the most common co- morbid condition associated with diabetes. Drugs that cause electrolyte imbalance especially diuretics should be used with caution in the elderly as they are prone to develop electrolyte imbalance. Patients with hyponatremia are often asymptomatic. It is also important to note that even mild hyponatremia may potentially lead to adverse outcomes. Serum electrolytes should be measured in every admitted elderly diabetic patient irrespective of the cause of admission. Because there are many causes of hyponatremia and the treatment differs according to the cause, a logical and efficient approach to the evaluation of patients with hyponatremia is imperative.

\section{References}

1. Field MJ, Burnett L, Sullivan DR, Stewart P. Clinical Biochemistry and Metabolism. In: Colledge NR, Walker BR Ralston SH, editors. Davidson's Principle and Practice of Medicine. 21 $1^{\text {st }}$ International ed. Churchill Livingstone Elsevier;2010:pp.435-446.

2. Kerry CC. Electrolyte and Acid-Base Disorders. In: McPhee SJ, Papadakis MA, Rabow MW editors. Current Medical Diagnosis and Treatment. 51 ${ }^{\text {st }}$ ed. New York: Mc Graw Hill; 2012:pp.848-856.

3. Janicic N, Verbalis JG. Evaluation and management of hypoosmolality in hospitalized patients. Endocrinol Metab Clin North Am. 2003;32:459-481.

4. 5. Mount DB. Fluid and Electrolyte Disturbances. In : Long DL, Fauci A, Kasper D, Hauser SL, Jameson JL, Loscalzo J editors. Harrison's Principles of Internal Medicine. 18th ed. New York: McGraw-Hill; 2012:pp.344-359.

5. John P, Kugler, Hustead T. Hyponatremia and Hypernatremia in the Elderly. Am Fam Physician. 2000 Jun 15;61(12):3623-3630.

6. Adrogué HJ, Madias NE. Primary Care: Hyponatremia. N Engl J Med 2000; 342:1581-1589.

7. Roscoe J M, Halperin M L, Rolleston F S, Goldstein M B. Hyperglycemia-induced hyponatremia: metabolic considerations in calculation of serum sodium depression. CMAJ. 1975 Feb;112: 452- 453.

8. Hillier TA, Abbott RD, Barrett EJ: Hyponatremia: evaluating the correction factor for hyperglycemia. Am J Med. 1999;106:399-403.

9. Chung HM, Kluge R, Schrier RW, Anderson RJ. Postoperative hyponatremia. A prospective study. Arch Inter Med. 1986;146:333-36.

10. Arieff AI. Hyponatremia, convulsions, respiratory arrest, and permanent brain damage after elective surgery in healthy women. N Engl J Med. 1986;314:1529-35.

11. Arieff AI, Ayus JC, Fraser CL. Hyponatraemia and death or permanent brain damage in healthy children. BMJ. 1992;304:1218-22.

12. Ayus JC, Wheeler JM, Arieff AI. Postoperative hyponatremic encephalopathy in menstruant women. 
Ann Intern Med. 1992;117:891-897.

13. Rao MY, Sudhir U, Kumar TA, Saravanan S, Mahesh E, Punith K. Hospital-Based Descriptive Study of Symptomatic Hyponatremia in Elderly Patients. JAPI. 2010 (Nov); 58:667-669.

14. Clayton JA, Le Jeune IR, Hall IP. Severe hyponatremia in medical in-patients: etiology, assessment and outcome. QJ Med. 2006;99:505-511.

15. Ayus JC, Arieff Al. Chronic hyponatremic encephalopathy in postmenopausal women: association of therapies with morbidity and mortality. JAMA. 1999;281:2299-2304

16. Tareen N, Martins D, Nagami G, Levine B, Norris KC. Sodium Disorders in the Elderly. J NatI Med Assoc. 2005;97:217-224.

17. Haque H, Amin MG, Uddin KN, Ahmed JU, Ahmed AKMS, Rahim MA et al. Pattern of electrolyte imbalance in hospitalized patients: experience in tertiary care hospital. Birdem Med J. 2012;2(1):14-18.
18. Agarwal M, Lynn KL, Richards AM, Nicholls G. Hyponatremic-Hypertensive Syndrome with Renal Ischemia: An Under recognized Disorder. Hypertension. 1999;33;1020-1024.

19. Reynolds RM, Padfield PL, Seckl JR. Disorders of sodium balance. BMJ. 2006;332:702-5.

20. Renneboog B, Musch W, Vandemergel X, Manto MU, Decaux G. Mild chronic hyponatremia is associated with falls, unsteadiness, and attention deficits. Am J Med 2006; 119: e1-e8.

21. Gankam Kengne F, Andres C, Sattar L, Melot C, Decaux G. Mild hyponatremia and risk of fracture in the ambulatory elderly. QJM 2008; 101: 583-588.

22. Verbalis JG, Barsony J, Sugimura Y, Tian Y, Adams DJ, Carter EA, Resnick HE. Hyponatremia-induced osteoporosis. J Bone Miner Res. 2010; 25: 554-563.

23. Kinsella S, Moran S, Sullivan MO, Molloy MG, Eustace JA. Hyponatremia independent of osteoporosis is associated with fracture occurrence. Clin J Am Soc Nephrol. 2010; 5: 275-280. 